\title{
Mortality and morbidity meetings: an untapped resource for improving the governance of patient safety?
}

\author{
Juliet Higginson, Rhiannon Walters, Naomi Fulop
}

- Additional appendices are published online only. To view these files please visit the journal online (http:// qualitysafety.bmj.com/ content/21/7.toc).

NIHR King's Patient Safety and Service Quality Research Centre, King's College London, London, UK

Correspondence to Professor Naomi Fulop, Department of Applied Health Research, University College London, 1-19 Torrington Place, London WC1E 7HB, UK; n.fulop@ucl.ac.uk

Accepted 27 March 2012 Published Online First 3 May 2012

\section{ABSTRACT}

Introduction: National Health Service hospitals and government agencies are increasingly using mortality rates to monitor the quality of inpatient care. Mortality and Morbidity (M\&M) meetings, established to review deaths as part of professional learning, have the potential to provide hospital boards with the assurance that patients are not dying as a consequence of unsafe clinical practices. This paper examines whether and how these meetings can contribute to the governance of patient safety.

Methods: To understand the arrangement and role of M\&M meetings in an English hospital, non-participant observations of meetings $(n=9)$ and semistructured interviews with meeting chairs $(n=19)$ were carried out. Following this, a structured mortality review process was codesigned and introduced into three clinical specialties over 12 months. A qualitative approach of observations $(n=30)$ and interviews $(n=40)$ was used to examine the impact on meetings and on frontline clinicians, managers and board members.

Findings: The initial study of M\&M meetings showed a considerable variation in the way deaths were reviewed and a lack of integration of these meetings into the hospital's governance framework. The introduction of the standardised mortality review process strengthened these processes. Clinicians supported its inclusion into M\&M meetings and managers and board members saw that a standardised trust-wide process offered greater levels of assurance. Conclusion: M\&M meetings already exist in many healthcare organisations and provide a governance resource that is underutilised. They can improve accountability of mortality data and support quality improvement without compromising professional learning, especially when facilitated by a standardised mortality review process.

\section{INTRODUCTION}

This paper is freely available online under the BMJ Journals unlocked scheme, see http://qualitysafety.bmj. com/site/about/unlocked. xhtml
In recent years, there has been an increasing international interest in using mortality rates to monitor the quality of hospital care. ${ }^{12}$ Concern about patient safety and scrutiny of mortality rates intensified in the UK with the extensive coverage of investigations into National Health Service (NHS) hospital failures and the Dr Foster report with its patient safety rating for NHS trusts. ${ }^{3} 4$ As a consequence, boards of healthcare organisations now require assurance that the care they provide is safe and that patients are not dying through failure of their services. Many trusts include mortality rates in their performance scorecards or dashboards and actively engage with national patient safety improvement initiatives, such as Patient Safety First and Safer Patient Initiative, to reduce mortality rates. ${ }^{5} 6$

A forum that has traditionally reviewed inhospital deaths is the long-standing Mortality and Morbidity (M\&M) meeting established by surgeons to further professional education. In regularly reviewing deaths and complications, these meetings have the potential to provide accountability and the necessary improvement measures required for patient safety as well as professional learning. How effective they are in fulfilling these additional roles remains unexplored.

In many countries, M\&M meetings are embedded within the medical curriculum for doctors in training. ${ }^{7}$ Junior doctors present cases to other doctors for reflection on diagnostic or treatment decision-making, and in return they receive clinicopathological wisdom and learn presentation skills. In the past, the brief discussions between the clinicians about the causes of death were thought to be effective peer review and an adequate means of changing practice. ${ }^{8}{ }^{9}$ Little attention was paid to analysing the causes of deaths for quality improvement. ${ }^{10}{ }^{11}$ Studies have shown that for M\&M meetings to facilitate improvement and be more than a forum for peer review, they need to be structured and systematic in reviewing and discussing deaths, 
directing discussions towards improving system and process variations. ${ }^{12-14}$ Studies recommended that to support this, junior doctors' training should include more focus on systematic process change and less on medical error in M\&M meetings. ${ }^{15-17}$

Historically, M\&M meetings have been led and attended only by the medical profession and have remained autonomous, with knowledge not being available or shared with other professions or across the wider hospital governance framework. This 'silo' working has led to a lack of organisational learning and accountability. ${ }^{18}$ Increasingly hospitals are beginning to integrate M\&M meetings into their governance processes, by making them mandatory and more accountable for reviewing deaths and taking corrective action should adverse events arise. ${ }^{19-21}$ To support this, the US Agency for Healthcare Research and Quality has produced web-based guidance for case analysis. ${ }^{22}$

Traditionally, adverse outcomes discussed at M\&M meetings have been attributed to individual competence in treating patients rather than the system or process failures involved with the care. ${ }^{11}{ }^{23}$ Although both contribute to errors, the focus on individuals has led clinicians to fear embarrassment and loss of reputation, making them reluctant to speak openly about errors at meetings. ${ }^{2425}$ This defensive behaviour is thought to be counterproductive to eliminating adverse events and assuring safe care. ${ }^{26} 27$

In light of this evidence we wanted to see whether and how M\&M meetings in an English teaching hospital could facilitate quality improvement, be accountable and provide assurance within the organisation's governance processes. Using a structured mortality review process as a facilitating mechanism, we wanted to assess what impact this would have on the original focus of the meetings and on professional learning; to explore how hospital staff viewed the changes; and evaluate the potential that a different format of M\&M meeting could offer the organisation.

\section{METHODS}

\section{Setting}

The participating organisation was an English NHS teaching hospital offering specialist tertiary services in addition to general and surgical care. The study was carried out in close collaboration with the hospital to inform and support other strategies for reducing mortality rates. The single case study allowed us to study both horizontally (ie, across divisions) and vertically (up and down the managerial and professional hierarchies) within the organisation and this approach allowed us to make analytic generalisations rather than statistical ones. $^{28}$

\section{Initial assessment}

During 2009, we studied the characteristics and processes of all the hospital M\&M meetings and their position within the governance framework using nonparticipant observations at meetings $(n=9)$ and semistructured interviews with meeting chairs and governance managers $(n=19)$. The results showed considerable variation in meeting structure, format and case presentations, confirming the findings from previous studies. We found that the responsibility for managing these meetings was devolved to clinical groups and as a consequence they had developed independently and in individual ways. There was no formal reporting structure from these meetings into the wider hospital governance to inform or assure the board that deaths were not occurring as a result of unsafe care.

Following this we codeveloped a standardised mortality review form and database with hospital staff, based on recommendations in the literature and drawing on the method of examining death used by the National Confidential Enquiry into Patient Outcome and Death and the Scottish Audit of Surgical Mortality. ${ }^{29-32}$ The review form focused on whether the death was avoidable; on issues arising from the care of the patient; and on whether these could have contributed to the patient's death. It recorded where actions were necessary to address any problems; whether an adverse incident report was needed; and who was going to take any actions forward (Mortality review form: Appendix 1, web only). We developed and piloted the review form and database which were then introduced into three clinical specialties selected purposively for their patient cohort. This process was carried out from January to December 2010 during which time we studied whether and how this standardised mortality review process supported M\&M meetings to contribute to wider governance processes.

\section{Participants}

Five care groups across two divisions agreed to participate in the study. Three care groups agreed to adopt a standardised mortality review process, two from a general medical division and one from a specialist division. One group in each division agreed to be a study control and not implement the review process but participate in the evaluation process. The two clinical divisions were selected to participate because they regularly experienced high numbers of deaths albeit for contrasting reasons. Patients admitted to the general medical division had a range of complex medical problems and multiple comorbidities, were often frail and elderly and had numerous possible causes of death. In contrast, patients admitted into the second division, which offered specialist tertiary services, had a narrower range of specialty-specific causes of death, such as acute or end-stage organ failure. 


\section{Data collection}

We used qualitative methods, interviews and observations to understand how and whether the standard mortality review process was or was not used, and how and whether it supported M\&M meetings in contributing to governance.

Forty semistructured interviews were carried out by the researcher $(\mathrm{JH})$, including frontline staff $(\mathrm{n}=32)$ and at senior executive level $(n=8)$. (Interview schedule: Appendix 2, web only). Participants were recruited with the aim of acquiring a broad sample across professional and occupational groups (Sampling matrix: Appendix 3, web only). Interviews were carried out with Chairs of M\&M meetings $(n=5)$ as well as a range of consultants $(n=6)$, junior doctors $(n=6)$, nursing staff $(n=7)$ who attended the meetings, and some who were not invited, to capture a wide range of experiences and views. Managers and senior clinicians $(n=8)$, senior executives and board members $(n=8)$ were selected because of their governance role.

Interviewees were provided with study details when they were invited to participate and were assured of anonymity and confidentiality. Consent to participating and being recorded was obtained at the start of the interview. Interviews lasted approximately $45 \mathrm{~min}$. Frontline staff interviewees were asked to identify the role and format of M\&M meetings; the importance of quality improvement in making care safer; views about the introduction of the review form and process; and the governance of M\&M meeting outcomes and accountability. Senior executives were asked what patient safety data they currently received; the role that M\&M meetings played in providing that data; and how they perceived the potential for a standardised process for reviewing deaths in the hospital governance of patient safety.

In addition to the interviews, we used non-participant observations at $M \& M(n=26)$ and governance $(n=4)$ meetings to provide background and context to the interviewees' comments. Consent for these was obtained prior to commencing the data collection.

\section{Data analysis}

Observations were organised in Microsoft Excel. Data from interviews were dual coded (JH and RW), generating inductive and deductive themes, which were agreed with a third researcher (NF) who read a sample of transcripts. Data were organised and analysed using NVivo 9 software.

\section{FINDINGS}

Two of the three specialties implemented the review process throughout the study. The remaining specialty helped with the development of the process but refrained from testing the final version. We present our findings under the following three main headings: how M\&M meetings contributed to the governance of patient safety within the hospital; how M\&M meetings provided a resource for learning and accountability; and what impact the standardised review process had on both activities.

\section{THE CONTRIBUTION OF M\&M MEETINGS TO THE GOVERNANCE OF MORTALITY DATA}

During the study, changes occurred in the governance of mortality data at both trust and divisional levels of the organisation as shown in figure 1. The left hand side of the figure outlines the prestudy governance processes for mortality data within the general medical division and hospital and shows no upward reporting from divisions to the hospital board and only informal cascading of information down to frontline staff. The right hand side shows the changes to governance introduced during the course of the study.

A monthly high-level trust safety committee was established to monitor externally published risk adjusted mortality rates, investigate outliers identified by the national regulator (the Care Quality Commission) and receive 6-monthly divisional reports from $\mathrm{M} \& \mathrm{M}$ meetings. It provided quarterly reports and assurance to a quality subcommittee of the board. M\&M meetings within each division began reporting quarterly to the divisional risk and governance committee, using outcome measures produced from the standardised review process. Improvement measures determined by the M\&M meetings were communicated to the frontline staff through newly established ward-based specialty governance and clinical management meetings. This strengthening of divisional and hospital governance arrangements may have been shaped in part by participation in, and feedback from, the study and a greater awareness of the potential of M\&M meetings to contribute to governance.

All interviewees agreed that senior executives and board members should be accountable for the safety of patient care, especially when 'things went wrong', and that reporting outcomes from $M \& M$ meetings to a trust committee necessary. Illustrative interview quotes are shown in box 1 .

M\&M participants viewed reporting to this Safety Monitoring Committee as acceptable provided that the environment was non-judgemental and understanding of the case mix of their patients. Some clinicians and managers appreciated the committee's focus on data while others wished for an opportunity to share learning from other specialties, escalate unresolved issues and receive support for change. This was contrary to the 
Figure 1 Changes to the governance of mortality data during the study.

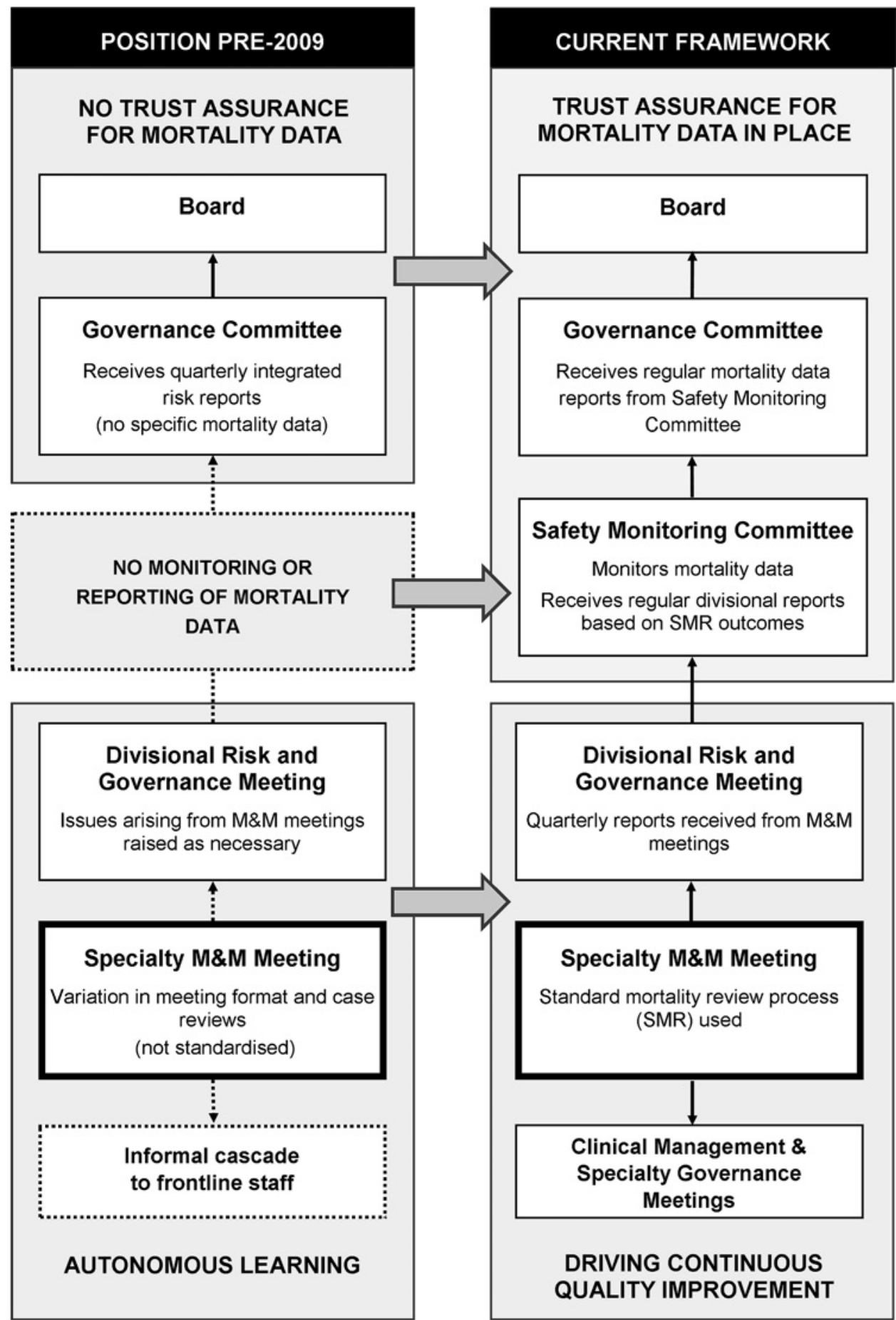

views of two senior executives who thought the role of the committee was to monitor mortality rates, and that it was the divisions' responsibility to address quality and safety issues.

\section{M\&M MEETINGS AS A RESOURCE FOR LEARNING, IMPROVEMENT AND ACCOUNTABILITY}

Observations of M\&M meetings during January to December 2010 showed considerable variation in the structure, organisation and the process of reviewing deaths as shown in tables 1 and 2. Responsibility for the meetings was devolved to the specialties which had led them to be non-standard and autonomous.

\section{Meeting frequency}

Clinical staff found weekly meetings helpful as the cases were still fresh in their minds and the small number allowed time for indepth discussion. However, the chair of a meeting that met monthly suggested that weekly meetings were less 'special' and would lose their impact. 
Box 1 The contribution of Mortality and Morbidity

meetings to the governance of mortality data

'Obviously, it's very important for the trust to know what's going on mortality-wise across the entire trust. And actually I don't think you can have meetings that are about such a significant area of care without that going to a higher group of people. It's all very well to say yes well we've got mortality meetings in all of the divisions and they're all going fine, but how does anybody know? ... Because at the end of the day they're going to be the ones who are answering the phone when the press sort of ring up and say ah we hear that your standardised mortality ratio is through the roof!' (Consultant).

'I think that information from these meetings can provide assurance that we don't have excess deaths. It helps us to pre-empt problems perhaps before we are alerted. By looking at morbidity cases we can also try to avoid problems before they lead to a fatality.' (Chair, Safety Monitoring Committee).

'I think that it's really important to ... know that we have learned from the experience, and so how you capture that and reassure management that we won't make the same mistake again is really important...' (Board member).

\section{Venue}

To encourage attendance, meetings were held at lunchtime or during working hours as part of the department's education programme. One specialty held their M\&M review as part of a larger management meeting that considered adverse incidents, complaints and other 'bad bits' of the service. Incorporating mortality reviews had the benefit of integrating and addressing all risk issues together, especially as it had 'all the right people round the table' to achieve changes. It reduced the number of meetings that clinicians with managerial responsibilities had to attend but had the disadvantage of not being open to all clinical staff.

The various ways in which M\&M meetings reviewed deaths is summarised in table 2. One control group M\&M meeting had already identified a need for a structured approach to their meetings and developed its own system for categorising deaths. However, this system did not identify the specific failures in care or action needed to address them.

\section{Case presentations}

Generally, junior doctors were tasked with reviewing deaths prior to meetings and presenting a summary of each case at the meetings. In one instance, 40 cases were presented in an hour and was 'mind-numbingly boring' according to one clinician. There was no time for indepth discussions making the review a tick box ceremony with errors liable to be 'swept under the table'. As

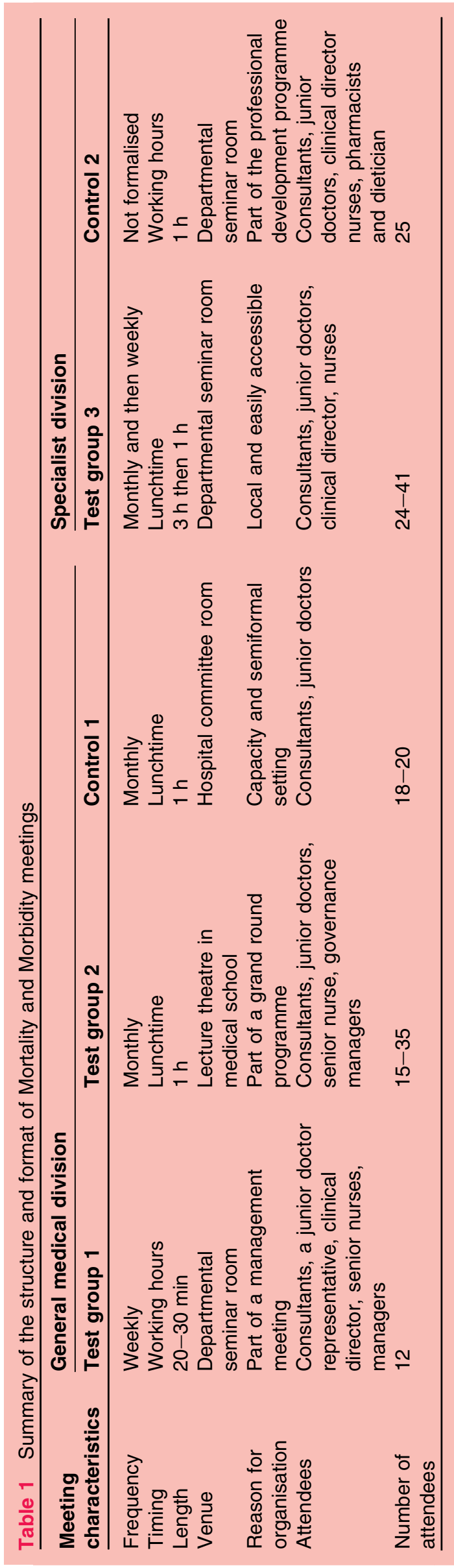

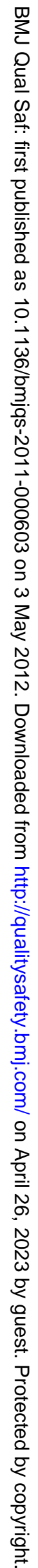




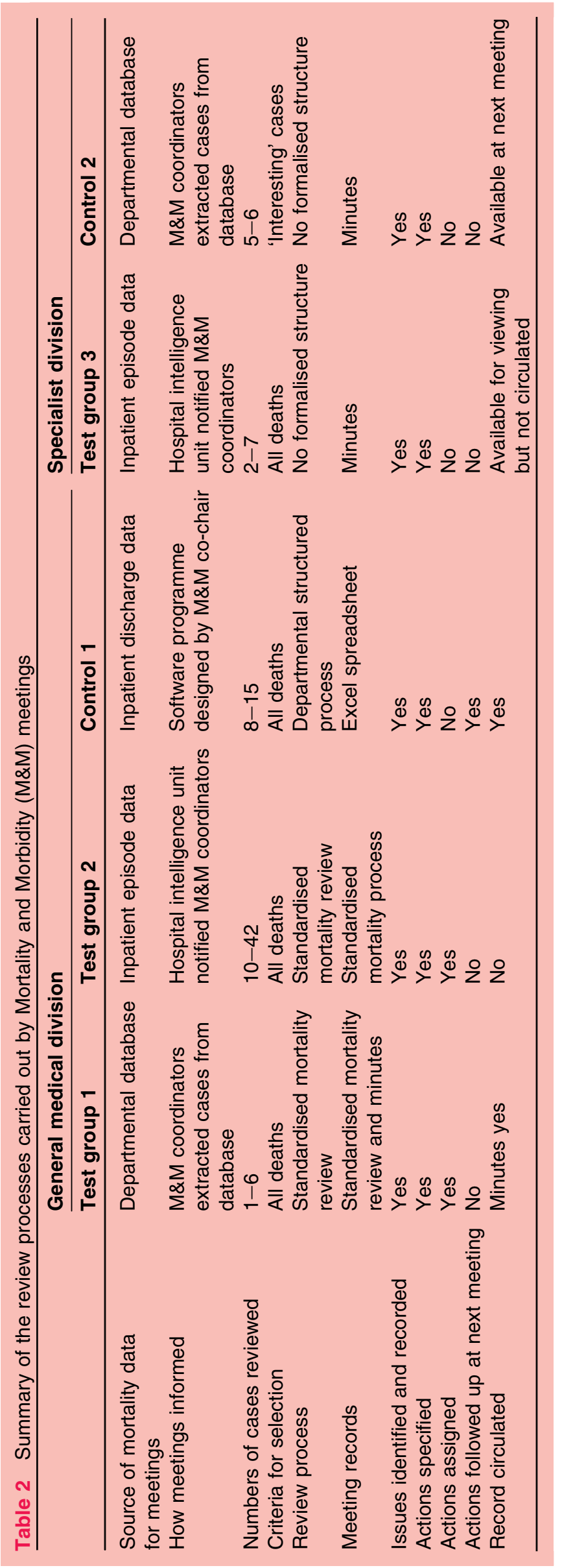

peer review was also important to clinicians, many felt that all deaths should be presented to a wide audience. Achieving a balance between scrutinising all deaths by more than one person, and selecting and discussing avoidable deaths in depth, appeared to be challenging.

\section{Participation and culture}

Both doctors and nurses reported that it was important to know which cases were going to be discussed at meetings. They wanted to familiarise themselves with the relevant case details to 'defend' any course of action that they had, or had not taken and for nurses especially, to give them the confidence to participate. All interviewees stressed that M\&M meetings should be blame-free to facilitate improvement and accountability, although some were not sure that this was true of their meetings. One control group had made a deliberate decision to develop a safe and non-critical environment before considering any other aspect of the meeting.

\section{Accountability}

All the participants saw learning and improvement in care as the purpose of M\&M meetings and an essential part of the clinical activity. Many saw them as having an additional governance role as shown in box 2. There were no reports that the educational and learning role of the M\&M meeting was compromised by a greater focus on accountability.

\section{THE IMPACT OF THE STANDARDISED MORTALITY REVIEW PROCESS}

\section{Improved structure to meetings}

Case reviewers liked how the standardised process directed the line of questioning and made it easier to extract the relevant information from case notes. Some thought it was helpful as a teaching aid for junior doctors. It highlighted and captured areas of concern and helped to focus and structure the meeting: 'helps stop the rambling'. Many thought this was what was needed in their meetings, as described in box 3 .

\section{Improved case review}

The review process brought standardisation to the examination of deaths and provided a framework that could be applied to patient deaths in different circumstances. It also provided an assurance that all deaths were reviewed in the same way, a fact that board members viewed positively. It gave the meetings more significance and made them 'official', reported one person, 'not just a paper exercise'. To maintain transparency in meetings clinicians suggested that the review form should be completed openly in the meeting. 
Box 2 Mortality and Morbidity (M\&M) meetings as a resource for learning and accountability

'I think the potential for them (M\&M meetings) is absolutely massive. I think if we have a culture of openness and discussing these cases that are very difficult in a very frank robust way, and junior doctors and hopefully other staff come to that and see that discussion, take (learning) away with them, then I think that's very powerful. And I think that if we're able to look at trends and patterns, then you can also use that to influence policy or practice within the division and within our wards and within our daily work.' (Consultant).

'In terms of reporting, I think ... the Trust should know exactly what is happening just as we should as clinicians' (Chair, M\&M meeting).

'Everything should be transparent; what you are doing well and what can be improved. If there are failings in the system it should be readily available for board members.' (Junior doctor).

'I think the big driver (for M\&M meetings) would be about improving patient outcomes... and linking it to the governance agenda, patient safety and patient experience and that would be how I, and ward managers, should be engaged in the process.' (Nurse).

'I guess if I look back I kind of wonder how on earth we thought we had assurance of any description before we started having robust M\&Ms. I guess the reality is we didn't question too hard and had we questioned we'd have said no we didn't have any assurance. So they have a very important role.' (Senior manager).

\section{Improved records}

The electronic record of the standardised mortality review facilitated easier reporting and the identification of themes of issues over time. Clinicians spoke of its capacity to formalise 'organisational memory', those issues that arose infrequently and were only remembered by long-standing members of staff. Actions needed and assigned were more formally recorded, and in doing so improved the likelihood of corrective measures being undertaken. Equally important was the paper trail it provided of how problems were addressed and practice had changed.

Box 3 The impact of the standardised process on Mortality and Morbidity meetings

'I think they've become much more structured, and again that's been partly helped by the fact that we have a form that actually provides a framework. I think without that things become very woolly; people can kind of get bogged down in looking at the micro aspects of morbidity and mortality, and not necessarily the bigger picture.' (Manager).
Improved reporting and governance

Chairs and managers of the participating groups were especially positive about the support the process offered in producing performance reports for the trust Safety Monitoring Committee. M\&M meeting outcomes-the number of avoidable deaths, contributory factors and actions taken to address any quality issues-were included in their twice-yearly report and were later developed into a standard reporting template by the committee.

One of the intervention groups in the general medical division identified a continuing problem with care which was identified through a more structured mortality review and addressed through an improved governance structure. This is outlined in box 4 .

\section{Standardised process}

Many clinicians, and especially board members, saw the benefit of having a standardised process across the hospital to provide reassurance that all deaths were being reviewed in the same way. The majority of those interviewed wanted to see the review process extended to all hospital M\&M meetings. Some participants of the control group M\&M meetings, who had no experience of using the process, felt that if it was rigorously completed, the data would provide 'clear performance metrics which could be hugely valuable to the organisation'.

\section{Concerns}

There were a few less-positive comments from staff who had not experienced the review process first-hand. The specialty that decided not to continue testing the study review felt it would not advance their own process and might limit the openness of the discussion, thus jeopardising the 'fragile culture' of their meeting.

Some meeting participants expressed concern that completing the review might become the focus of the meeting rather than it being an aid to direct discussion. Extra administrative support might also be needed. Others suggested that specialties might wish to add specialty-specific questions to the core template. Overall, the concerns were outweighed by support for the process.

\section{DISCUSSION}

M\&M meetings are an established part of medical education and have existed for decades as forums for doctors to review and present cases for biomedical exploration. Their potential for quality improvement depends on them being more structured and reviewing deaths in a more systematic way. Changes to the curriculum of junior doctors' professional education have done much to promote this. ${ }^{24} 33$ Studies have also shown how specialty or departmental M\&M 
Box 4 An example of a change in practice in the division with improved governance

At a monthly departmental Mortality and Morbidity (M\&M) meeting, all 22 deaths from the previous month were presented. These cases had been reviewed by two junior doctors in consultation with the M\&M meeting chair. The junior doctors presented a summary of each case on a single PowerPoint slide, describing clinical details and causes of death. In four of the 22 cases, where the patients were not expected to die, the meeting chair led a greater examination and discussion. In one of these cases, an acutely ill patient admitted to a medical ward had not received the appropriate timely specialist input despite a referral having been made. The M\&M meeting agreed that this omission constituted poor clinical care which potentially contributed to the death. 'Process issues and communication' were attributed to the lack of response to the referral. The case was also reviewed in the corresponding specialist $M \& M$ meeting.

Action

1. Specialty consultant invited to the next M\&M meeting for an open discussion.

2. Referral guidelines to be produced jointly by the two departments.

Problem repeated

1. Failure to get prompt specialist input on a further occasion.

Action

1. Chair raised the issue at a quarterly divisional $M \& M$ meeting: clinical director advised specialist divisions of the need for compliance with new referral guidance.

2. Chair reported problem in his 6-monthly feedback to the trust Safety Monitoring Committee for hospital-wide compliance with the referral guidance.

meetings have improved quality by adopting structured reviews. ${ }^{14} 2335$ Our findings build on these and show how M\&M meetings can be integrated across the whole hospital and contribute to the accountability for deaths and governance of patient safety. Meetings that adopt a standardised and systematic review process can focus on systems and process failures; provide a record of meeting outcomes and follow-up actions taken to address failures; and facilitate the reporting of meeting outcomes and assurance to the board.

We had anticipated that there might be greater resistance from clinicians, who would want to maintain their autonomy and not want to codify and share sensitive data. ${ }^{36}$ Our findings show considerable support from them for both the standardised review process and the wider governance role of M\&M meetings. There may be several reasons for a greater acceptance than expected. Health professionals are expected to take responsibility for governance of their own clinical practice and are increasingly aware that hospitals are being monitored for the quality of their care. ${ }^{38}$ Many are being co-opted into managerial roles such as clinical directors, medical directors and chairs of governance committees and are accountable for the governance of quality and safety data. ${ }^{36}$ This additional managerial responsibility encourages clinicians to value systems that make the provision of governance data easier.

The standard review process was generally accepted because it met with clinicians' requirements to capture the tacit nature of case context and complexity. ${ }^{18} 26$ Unlike many checklists it was adapted to their particular contextual needs which gave them ownership. ${ }^{40}$ Close collaboration during its development also helped to increase engagement and was seen less as a top-down imposition. ${ }^{41}{ }^{42}$ Health professionals welcomed the focus on systems and process failures and away from individual competence, while senior executives and board members appreciated the standardisation and safety monitoring that the process supported. ${ }^{43}$ Suggestions for an M\&M meeting review process that facilitates both learning and assurance, based on our findings, are listed in box 5 .

Although this is a single case study, personal communications with medical directors of four other NHS trusts championing patient safety helped place our findings into context. As with our case study, responsibility for M\&M meetings in these hospitals had previously been devolved to clinicians and provided no assurance that deaths were being reviewed in a systematic and rigorous way. Outcomes from meetings were neither standardised nor integrated into the hospital governance. In the smaller hospitals, there was an increased focus on reviewing and following up deaths but this was carried

Box 5 Suggestions for using Mortality and Morbidity (M\&M) meetings for governance of patient safety

- Invite all types of health professionals to M\&M meetings and notify them in advance which cases are to be reviewed and discussed.

- Employ a short, standardised review process that highlights avoidable deaths and contributory factors, allowing for staff involvement in the design and flexibility for specialty-specific questions as necessary.

- Allow adequate time for case discussions using the review questions as an aid.

- Encourage a focus on systems and process variations and not individual competence.

- Carry out the review openly, summarising actions at the end of the meeting and tracking them at the following one.

- Record meeting outcomes electronically to facilitate audit and performance data.

- Integrate M\&M meetings into the wider governance structure and monitor meeting outcomes for shared learning and assurance. 
out by individual senior clinicians. However, the larger hospitals were beginning to see the need for a more effective way of reviewing larger numbers of deaths and the important role that M\&M meetings could play, and were introducing standard trust-wide review processes.

\section{CONCLUSION}

M\&M meetings have the potential to contribute to the governance of patient safety. They exist in many healthcare organisations and are a governance resource that is generally underutilised. They can improve the accountability of mortality data and support quality improvement without compromising professional learning, especially when facilitated by a standardised mortality review process. ${ }^{44}$

Acknowledgements The research team would like to thank all the hospital staff who contributed to the research, and members of the PSSQ team for their helpful comments on earlier drafts of the paper.

Contributors $\mathrm{JH}$ was involved in the conception and study design; data collection, analysis and interpretation; and was the main author. RW contributed to the analysis and interpretation of the data and drafting the paper. NF was involved in the conception and the study design, and contributed to the data analysis and drafting the paper.

Funding The NIHR King's Patient Safety and Service Quality Research Centre (King's PSSQ) is part of the National Institute for Health Research (NIHR) and is funded by the Department of Health.

Disclaimer This report presents independent research commissioned by the NIHR. The views expressed in this report are those of the authors and not necessarily those of the NHS, the NIHR or the Department of Health.

Competing interests All authors have completed the Unified Competing Interest form (available on request from the corresponding author) and declare: no support from any organisation for the submitted work; no financial relationships with any organisations that might have an interest in the submitted work in the previous 3 years; and no other relationships or activities that could appear to have influenced the submitted work.

Ethics approval NHS Ethical Approval Granted (REC ref 09/H0807/74).

Provenance and peer review Not commissioned; externally peer reviewed.

Data sharing statement Data are available on request from the corresponding author.

\section{REFERENCES}

1. The Canadian Institute for Health Information. HSMR: A New Approach for Measuring Hospital Mortality Trends in Canada. Ottawa: $\mathrm{ClHI}, 2007$.

2. Jarman $B$, Pieter $D$, van der Veen $A A$, et al. The hospital standardised mortality ratio: a powerful tool for Dutch hospitals to assess their quality of care? Qual Saf Health Care 2010;19:9-13.

3. Francis R. Independent Inquiry into Care Provided by Mid Staffordshire NHS Foundation Trust January 2005-March 2009. London:Stationery Office 2010.

4. Dr Foster Intelligence. The Dr Foster Hospital Guide 2009: How Safe is Your Hospital? London: Dr Foster Intelligence. 2009.

5. National Patient Safety Agency. Patient Safety First. The Campaign Review. London: National Patient Safety Agency, 2011.

6. The Health Foundation. Improvement in Practice: Making Our Hospitals Safer. London:The Health Foundation. 2009.

7. Accreditation Council for Graduate Education. ACGME Program Requirements for Graduate Medical Education in Surgery. 2008. http://www.acgme.org/acWebsite/downloads/RRC_progReq/ 440_general_surgery_01012008.pdf (accessed 5 Jan 2010).
8. Biddle C. Investigating the nature of the mortality and morbidity conference. Acad Med 1990;65:420.

9. Hopkins ES. The mortality and morbidity conference as a quality assurance mechanism: can $\mathrm{M}+\mathrm{M}=\mathrm{M}+\mathrm{E}$. J Qual Assur 1989;13:10-11,36.

10. Orlander JD, Fincke BG. Morbidity and mortality conference: a survey of academic internal medicine departments. J Gen Intern Med 2003;18:656-8.

11. Pierluissi E, Fischer MA, Campbell AR, et al. Discussion of medical errors in morbidity and mortality conferences. JAMA 2003;290:2838-42.

12. Batalden PB, Davidoff $F$. What is "quality improvement" and how can it transform healthcare? Qual Saf Health Care 2007;16:2-3.

13. Friedman JN, Pinard MS, Laxer RM. The morbidity and mortality conference in university-affiliated pediatric departments in Canada. J Pediatr 2005;146:1-2.

14. Schwarz D, Schwarz R, Gauchan B, et al. Implementing a systemsoriented morbidity and mortality conference in remote rural Nepal for quality improvement. BMJ Qual Saf 2011;20:1082-8.

15. Berenholtz SM, Hartsell TL, Pronovost PJ. Learning from defects to enhance morbidity and mortality conferences. Am J Med Qual 2009;24:1-4.

16. Deis JN, Smith MS, Warren MD, et al. Transforming the Morbidity and Mortality Conference into a System-Wide Improvement. Advances in Patient Safety: New Directions and Alternative Approaches. 2008. http://www.ahrq.gov/downloads/pub/advances2/vol2/AdvancesDeis_82.pdf (accessed 14 Jul 2009).

17. Hobgood C, Hevia A, Tamayo-Sarver JH, et al. The Influence of the causes and contexts of medical errors on emergency medicine residents' responses to their errors: an exploration. Acad Med 2005;80:758-64.

18. Currie G, Waring J, Finn R. The limits of knowledge management for UK public services modernisation: the case of patient safety and service quality. Public Admin 2008;86:363-85.

19. The Leeds Teaching Hospital NHS Trust Webpage. 2010. www. leedsth.nhs.uk/sites/equality/documents/MortalityandMorbidity.doc (accessed Oct 2010).

20. New Zealand Ministry of Health. Section 4: Morbidity and Mortality Review. 2008. http://www.moh.govt.nz/moh.nsf/UnidPrint/MH236? OpenDocument (accessed Jul 2009).

21. The Royal Childrens Hospital Melbourne. Guidelines for Mortality and Morbidity Review Meetings. 2010. http://www.rch.org.au/emplibrary/ quality/GuidelinesforMMreviewMarch2010.pdf (accessed Oct 2010).

22. Wachter RM, Shojania KG, Minichiello T, et al. AHRQ WebM\&M-Online Medical Error Reporting and Analysis. 2005. http://webmm.ahrq.gov (accessed Jun 2010).

23. Orlander JD, Barber TW, Fincke BG. The morbidity and mortality conference: the delicate nature of learning from error. Acad Med 2002;77:1001-6.

24. Wachter RM, Shojania KG, Saint S, et al. Learning from our mistakes: quality grand rounds, a new case-based series on medical errors and patient safety. Ann Intern Med 2002;136:850-2.

25. Kaldjian LC, Forman-Hoffman VL, Jones EW, et al. Do faculty and resident physicians discuss their medical errors? J Med Ethics 2008;34:717-22.

26. Leistikow IP, Kalkman CJ, de Bruijn $\mathrm{H}$. Why patient safety is such a tough nut to crack. BMJ 2011;342:d3447.

27. Cunningham $\mathrm{W}$, Wilson $\mathrm{H}$. Complaints, shame and defensive medicine. BMJ Qual Saf 2011;20:449-52.

28. Yin RK. Case Study Research: Design and Methods. 4th edition Sage Publications, Inc, London. 2009.

29. Aboumatar HJ, Blackledge CG Jr, Dickson C, et al. A descriptive study of morbidity and mortality conferences and their conformity to medical incident analysis models: results of the morbidity and mortality conference improvement study, phase 1. Am J Med Qual 2007;22:232-8.

30. National Confidential Enquiry into Patient Outcome and Death (NCEPOD). An acute problem? A report of the national confidential enquiry into patient outcome and death. Nurs Crit Care 2005; 10:225-7.

31. Scottish Audit of Surgical Mortality. Surgical Pro Forma-2007. http:// www.sasm.org.uk/Forms/Surgicalproforma2007.pdf (accessed Nov 2009).

32. Capital District Health Authority Nova Scotia. Mortality and Morbidity Rounds Process. 2005. http://www.cdha.nshealth.ca/defaultnc.aspx? page $=$ SearchResults\&querySessionld=Query2548_86\&siteld $=$ $1 \&$ siteFilter $=1 \&$ xslpath $=$ Resources $\% 5$ csite $x s \mid \%$ 5csearchresults_anycontent_w_redirect.xsl (accessed Nov 2009).

33. Kuper A, Nedden NZ, Etchells E, et al. Teaching and learning in morbidity and mortality rounds: an ethnographic study. Med Educ 2010;44:559-69.

34. Prince JM, Vallabhaneni R, Zenati MS, et al. Increased interactive format for Morbidity \& Mortality conference improves educational value and enhances confidence. J Surg Educ 2007;64:266-72. 
35. McDonnell C, Laxer RM, Roy WL. Redesigning a mortality and morbidity program in a university-affiliated pediatric anesthesia department. Jt Comm J Qual Patient Saf 2010;36:117-25.

36. Waring J, Currie G. Managing expert knowledge: organizational challenges and managerial futures for the UK medical profession. Organ Stud 2009;30:755-78.

37. Davies H, Powell A, Rushmer R. Why don't clinicians engage with quality improvement? J Health Serv Res Policy 2007;12:129-30.

38. Care Quality Commission. A New System of Registration. London: Care Quality Commission. 2010.

39. Monitor. Independent Regulator of NHS Foundation Trusts. Compliance Framework 2011-2012. London:Monitor. 2011.
40. Bosk CL, Dixon-Woods M, Goeschel CA, et al. Reality check for checklists. Lancet 2009;374:444-5.

41. Parand $\mathrm{A}$, Burnett $\mathrm{S}$, Benn J, et al. Medical engagement in organisation-wide safety and quality-improvement programmes: experience in the UK Safer Patients Initiative. Qual Saf Health Care 2010;19:e44.

42. Pronovost PJ. Navigating adaptive challenges in quality improvement. BMJ Qual Saf 2011;20:560-3.

43. Ikkersheim DE, Berg M. How reliable is your hospital? A qualitative framework for analysing reliability levels. BMJ Qual Saf 2011;20:785-90.

44. Lau H, Litman KC. Saving lives by studying deaths: using standardized mortality reviews to improve inpatient safety. Jt Comm J Qual Patient Saf 2011;37:400-8.

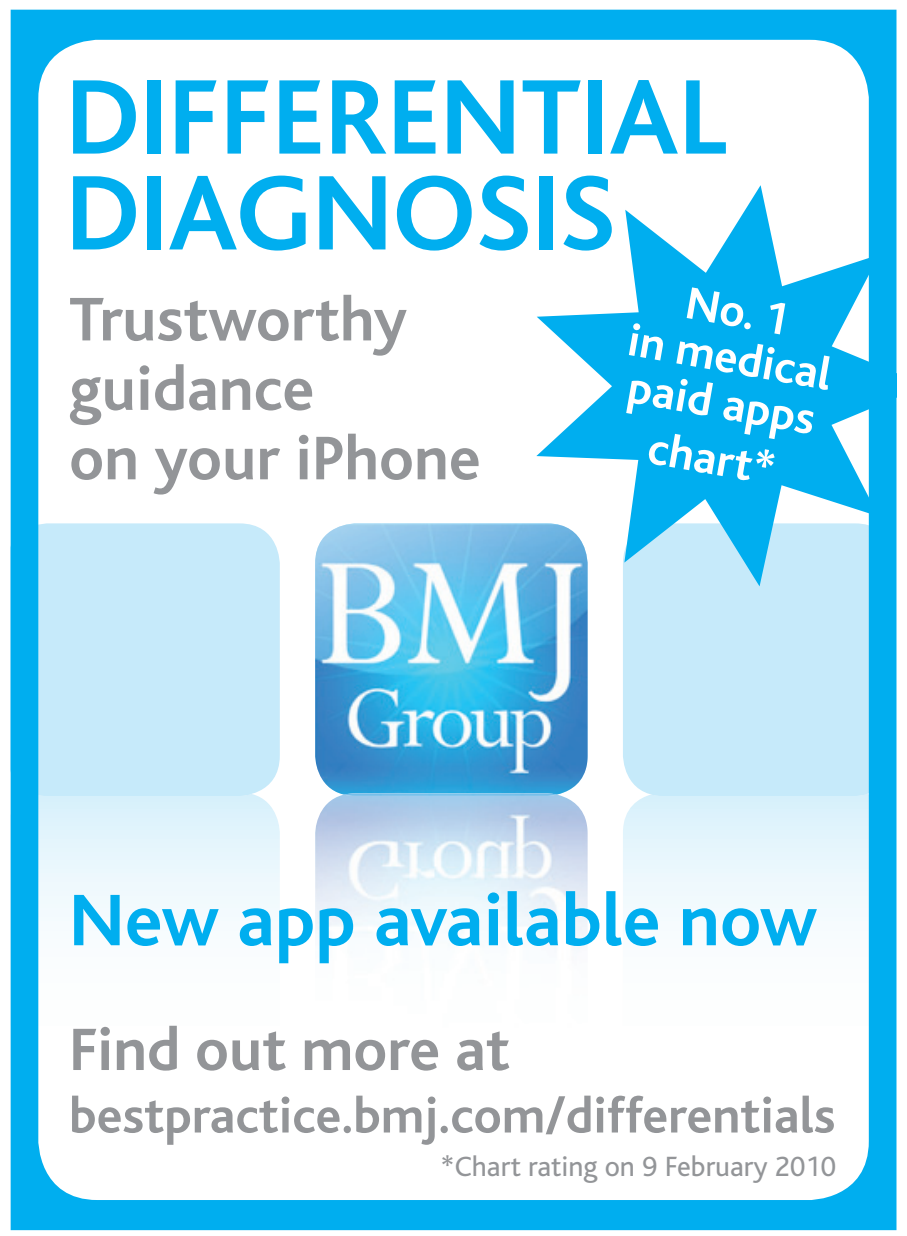

